\title{
Drogas potenciadoras para la búsqueda de la perfección
}

\section{Human enhancement drugs and the pursuit of perfection}

I Jim McVeigh; Michael Evans-Brown; Mark A. Bellis
Centre for Public Health
Liverpool John Moores University

\section{Resumen}

Hay un gran interés hacia serie de medicamentos usados para la mejora o potenciación de distintos aspectos de la condición humana, lo que les convierte en un nuevo problema de salud pública al que se ha prestado poca atención hasta ahora. En un intento por ser más fuertes, felices o inteligentes, o para parecer más delgados, más jóvenes o más bellos, la gente está recurriendo a diversos productos farmacéuticos. La amplia disponibilidad de fármacos con potencial para mejorar las capacidades humanas, la apariencia y las habilidades ha generado una nueva y cada vez mayor audiencia de usuarios. A diferencia de los usuarios de drogas como la heroina, la cocaina, etc., estos usuarios de este tipo de sustancias no necesariamente se perciben a sí mismos como 'usuarios de drogas'. Las personas atraidas por estos medicamentos pueden tener un escaso o ningún conocimiento sobre los peligros físicos o psicológicos asociados con estas sustancias o sobre su potencial adictivo. Además de los potentes efectos de muchos de estos medicamentos, existen considerables riesgos asociados a la naturaleza clandestina del mercado. El creciente número de medicamentos no evaluados, prohibidos o adulterados y la falta de garantías y de calidad en el proceso de fabricación ilegal ha dado lugar a serios problemas y muertes. La facilidad con que los productos farmacéuticos pueden ser fabricados y distribuidos, junto con los importantes beneficios que se pueden conseguir desde el mercado ilegal, se ha traducido en un creciente desafio para los responsables de las politicas y los sistemas de salud en muchos paises. Esta editorial tiene como objetivo dar a conocer esta nueva situación asociada a estas drogas potenciadoras y a ofrecer una breve visión de alguna de ellas y de los riesgos asociados.

Palabras clave: Drogas potenciadoras, anabolizantes, estilos de vida, mercado ilegal.

\author{
Enviar correspondencia a: \\ Jim McVeigh \\ Centre for Public Health, Research Directorate \\ Faculty of Health and Applied Social Science. \\ Liverpool John Moores University. \\ Henry Cotton Building. \\ 15-21 Webster Street. \\ L3 2ET LIVERPOOL \\ j.mcveigh@ljmu.ac.uk.www.cph.org.uk
}

\section{Abstract}

The emerging threat to public health posed by the use of human enhancement drugs has remained largely unrecognised. In attempts to become stronger, happier or smarter, or to look thinner, younger or more beautiful, people are turning to a diverse range of pharmaceuticals. The widespread availability of drugs with the potential to improve human attributes, appearance and abilities has generated a new and growing audience of users. Unlike users of drugs such as heroin, cocaine etc, users of human enhancement drugs do not necessarily perceive themselves as 'drug users'. Those attracted to these drugs may have little or no knowledge or understanding of the physical or psychological harm associated with these substances or their potential for addiction. In addition to the potent effects of many human enhancement drugs, there are considerable risks associated to the clandestine nature of the market. The growing number of untested, banned or adulterated drugs and the lack of safeguards and quality assurance in the illicit manufacturing process has resulted in serious harms and fatalities. The ease with which pharmaceuticals can be manufactured and distributed, combined with the significant profits that can be made from the illicit market, has resulted in a growing challenge for policy makers and health systems in many countries. This editorial aims to raise awareness of this emerging drugs situation and provide a brief overview of some of the drugs and their associated risks.

Key words: enhancement, public health, lifestyle, anabolic, drugs market. 
'It's a no-brainer - bring on the pills that will make us smarter'

(Marrin, 2010)

D rug use is often portrayed and perceived as a hedonistic pursuit of pleasure; whether through the use of thought-expanding hallucinogens, the excitement of stimulants or the euphoria of opiates. However, there are many drugs that are typically used neither as a means for instant gratification nor for the treatment of illness but instead to improve on an individual's appearance and ability. Collectively termed human enhancement drugs, these substances increasingly represent a challenge to public health and reflect a society that expects "a pill for every ill" and for some, the aim to be "better than well". The pursuit of excellence and the attempt to surpass one's natural potential is by no means a new phenomenon. In fact, throughout history the human condition has been characterised by man's endeavour to gain an advantage over his competitor and the environment. As long ago as the original Olympic Games, practices and rituals such as feasting on animal testicles have been employed to enhance the human condition. To an extent some fulfilled expectation; although often due to placebo effects heightened by religious and spiritual ceremony and beliefs. As a result, substances such as 'the rear hooves of an Abyssinian ass' used in ancient Egypt, became an ingrained element of a lifestyle or culture. While such examples are common throughout history, over the last decade what has happened globally is without precedent.

Diverse sections of the population are now obtaining relatively cheap drugs in an attempt to increase their intelligence and fitness, to look younger and more beautiful, or to improve their mood. Advances in technology and science together with developments in communication (in particular the internet), have made these drugs available to a growing number of individuals. Users of these drugs include students, academics, gym members and those wishing to lose weight; in fact anyone interested in pharmaceutical enhancement.

The potential impact of this rapid expansion of human enhancement drug use on population health, health care systems and society in general is considerable. Such drugs may be untested, have failed tests to exclude adverse effects, be adulterated with other drugs or not be what was advertised at all (World Health Organization, 2007). The properties of such drugs may be as physiologically or psychologically addictive as opium, a common component in $19^{\text {th }}$ century tonics (Berridge, 1978).

The widespread advertising, appeal and availability of enhancement drugs mean that for some, the whole concept of natural ageing is now redundant. For others, although "perfectly healthy" by traditional standards and definitions, there is a perceived inadequacy or infirmity in relation to strength, intelligence, mood or looks which requires treatment and improvement. Consequently, as with other drugs, as the demand for enhancement drugs grow the development of an underground market is inevitable. The potential profits are immense. Already the illicit market has flourished, not just as a result of developments in communication and transport networks, but due to the difficulties in controlling these drugs at both the manufacture and retail levels. Weak legal and regulatory systems as well as corruption in some countries have hampered the restriction of the market (World Health Organization, 2004). Even where robust legal and regulatory controls are established, enforcement is limited by the low priority given to this form of drug use.

This evolution of self-medication and the phenomenon of human enhancement drugs is a topic that has been explored and discussed by ethicists and philosophers (Savulescu, 2011) and has been a fertile ground for novelists and filmmakers. To date, it has been largely ignored by practitioners and academics within the field of drug misuse and addiction.

Human enhancement drugs pose a clear threat to public health. Similarly to the better-known illicit drugs (e.g. cannabis, heroin etc), many of the drugs have completely by-passed even the most rudimentary pharmaceutical safeguards. Many are often untested or have been banned. The unregulated nature of production and distribution has made contamination and substitution commonplace (EvansBrown, Kimergård \& McVeigh, 2009). Some of these drugs have been shown to cause severe health effects including fatalities while others are associated with dependence. This editorial provides an overview of how the pursuit of human enhancement is set to create new challenges in the field of human addiction.

\section{A Brief History}

'Do not carry that burden of excess fat when so many of the folks around you have found 'Marmola' the easiest way of all to reduce. Know once again the joy of a beautiful, slender figure and make summer days happy days' (Advert for

Marmola appearing in the UK Daily Mirror (1937)

The drive for perfection and the hope to remain at the pinnacle of our prowess are characteristics common to cultures both modern and ancient. While the methods vary between societies, the consumption of drugs to enhance abilities or appearance is widespread. The long history of enhancement drugs changed substantially in the late nineteenth and early twentieth century. This period saw a rapid growth in the trade of secret remedies and patent medicines (British Medical Association, 1909). These "cures" were sold directly to the consumer and consisted of a variety of products to treat conditions and illnesses that remain a focus of modern pharmaceutical research and investment. While the terminology has changed, self-medication to treat 'male weakness' (including erectile dysfunction and premature ejaculation), baldness and fatness continues. Along with substances for such specific conditions there 
were a range of tonics and elixirs to increase wellbeing and improve the quality of life. It is difficult to estimate how many people used enhancement products during the early twentieth century but a sense of scale is provided by 'sucker lists' (mailing lists of people who had previously bought such products) in the United States. For example, in 1915, authorities destroyed one 'sucker list' of 500,000 individuals as part of a court action against the fraudulent promotion of a cure for "male weakness", advertised as the "surest-acting combination for the cure of deficient manhood and vigour failure ever assembled" (Young, 1992).

Throughout the twentieth century a variety of legislative and regulatory systems were implemented, often in response to drug disasters such as thalidomide (a treatment for morning sickness in pregnancy) and to a lesser extent Elixir Sulfanilamide (an antibiotic) (Geiling \& Cannon, 1938) and Stalinon (to treat boils) ('Stalinon': a therapeutic disaster, 1958). Despite the increased requirements for the testing of medications prior to marketing and restrictions on the sale of potentially dangerous drugs, this did not curtail the widespread prescription of addictive amphetamines for the enhancement of energy levels, promotion of wellbeing and as an aid to weight loss during the 1950s and 1960s (Working Party on Amphetamine Preparations, 1968).

\section{Enhancement drugs in the 21st century}

'Who would have thought this product could be brilliant. MASSIVE THANKS ... for saving our relationship, continuing to give good service and keeping your prices so fair...' (Testimonial from online shop selling human enhancement drugs).

Despite the increasing use of drugs for weight loss and to enhance mood, during the latter part of the $20^{\text {th }}$ century, enhancement drugs were largely, the domain of the elite athlete or serious weight trainer. With the exception of a small number of specialist clinics predominantly in the United States, and doctors who were willing to prescribe for nontherapeutic purposes, anabolic steroids, growth hormones and associated drugs remained an underground and largely self-contained culture. However, the types of available human enhancement drugs and the reasons that they are employed (e.g. sibutramine for weight loss and melanotan II for skin tanning) have increased greatly in recent years, leading to diverse populations being attracted to their use. An important factor is likely to be the range of issues that have, in the space of a single generation, changed from being considered natural life events to medical conditions capable of being treated with drugs, either prescribed or self-directed. Ageing, fatness, sexual dysfunction, hair loss, shyness, fatigue and shortness are all conditions for which a cure is sought, even expected (Conrad, 2007). Allied to this is the contribution of the media in portraying stylised images and creating pressures to conform and excel, together with often sensationalist misrepresentations of the benefits of 'major breakthroughs' in pharmacological developments. These factors, combined with a readily available supply of products and sufficient expendable income, are perhaps key components in this emerging drugs issue.

The human enhancement drugs that are currently being used can be divided into six categories. Based on their main reason for use, these drugs are used to enhance:

- structure and function of muscle e.g. anabolic steroids and growth hormones to increase lean muscle mass;

- weight loss e.g. rimonabant or sibutramine to suppress appetite, 2,4-dinitrophenol (DNP) to burn fat;

- cosmetic appearance of the skin and hair e.g. mercurycontaining creams for skin lightening, melanotan II for an all year tan;

- sexual behaviour and function e.g. sildenafil to improve erection and bremelanotide to increase desire;

- cognitive function e.g. methylphenidate and modafinil to improve concentration and learning; and,

- mood and social behaviours e.g. paroxetine and fluoxetine to be 'better than well'.

Several of the above examples of drugs that are currently being used for enhancement also have legitimate therapeutic roles. However, it is the self-directed use of illicitly obtained drugs, which is the primary challenge to public health. It is important to differentiate between a drug's licensed role, for which it has been tested, approved, prescribed and dispensed and its illicit use as a human enhancement drug.

Some of these drugs are taken for more than one enhancement purpose, with those individuals who use the drug reporting a primary purpose of use, in addition to supplementary benefits. For instance the synthetic melanocortin analogue, melanotan II, is predominantly used by those wanting a cosmetic skin tan. However, it is not uncommon for users to report additional benefits of the drug as an aphrodisiac and as an appetite suppressant in order to help lose weight. There is a price to pay for these perceived benefits. Users have reported transient adverse effects such as facial flushing, nausea and vomiting. Of far greater concern is the (as yet unknown) potential for longer term physiological and psychological impact of the use of this hormone. Perhaps most concerning of all is the potential risks associated with the injection of melanotan II (EvansBrown, Dawson, Chandler \& McVeigh, 2009).

A number of interlinked factors have transformed the availability of human enhancement drugs. The explosion of low-cost pharmaceutical manufacturing capacity in countries such as China and India has provided a ready supply of constituent chemicals and affordable drugs (Evans-Brown, Kimergård \& McVeigh, 2009). Falling costs of producing and purchasing enhancement drugs are illustrated by the case of human growth hormone. Research in the 1990s indicated a price range on the UK illicit market of $€ 6.58-£ 20$ per IU (International Unit). By 2008, the price had fallen to $£ 1.00-$ £8.33 per IU (Evans-Brown, \& McVeigh, 2009). 
Globalisation of free trade and the development of communication and transport networks such as cargo and postal services have contributed significantly to the growth of the human enhancement drug industry. However, the internet is arguably an even more important driver in the rapid change of human enhancement drug use, from a niche sub-culture to an emerging challenge to population health. While more traditional methods of sale continue for some enhancement drugs (e.g. sales of skin-lightening via 'bricks and mortar' shops), the internet is integral to the enhancement drug market at both wholesale and retail levels. Those involved in the enhancement drug trade range from individuals engaged in 'cottage industries' to organized crime, with the internet facilitating the purchase of constituents they require, including base chemicals, packaging and presses or the finished pharmaceutical products.

While there is a lack of robust prevalence studies, enforcement activity suggests the current scale of the illicit market in human enhancement drugs is immense. Even as long ago as 2003, UK regulatory authorities found that eight of the top 10 prescription drugs supplied over the internet were human enhancement drugs (National Audit Office, 2003). By 2010, in the UK alone more than 8.5 million doses of counterfeit sildenafil, worth around $€ 13$ million, were seized. In one London Borough, during a six year period, 23 people were prosecuted for selling skin lightening cream, with total fines and confiscations amounting to $£ 336,000$. Additional indicators of demand can be drawn from studies examining use in general populations and within specific sectors. A large internet survey of men from Italy, the UK and Germany, found that over 3\% of men had used non-prescribed erectile dysfunction drugs, such as sildenafil, in the last six months (Schnetzler, Banks, Kirby, Zou \& Symonds, 2010). The willingness of people to purchase drugs on the internet as well as the related risks are shown by a straw poll of General Practitioners, which found that 25\% had treated patients for drug reactions after using medicines bought online. In the only area of the UK to have systematically recorded injecting equipment transactions since the early 1990s (Merseyside and Cheshire) there was more than a twenty-fold increase in the number of steroid injectors attending these services between 1991 and 2008, such that new clients for steroids now outnumber those for heroin.

\section{The harms associated with human enhancement drugs}

'...we withdrew one participant from the study after the

fifth week because he became alarmingly hypomanic and aggressive' (Study investigating the effects of testosterone on mood and aggression (Pope et al., 2001)

All drugs have the capacity to cause harm regardless of legality, purpose or motivation of use. Substances currently being used as human enhancement drugs are no exception and the mechanisms through which they are often illicitly produced and supplied increase the risk these drugs represent. Table 1 illustrates some of the more commonly used enhancement drugs together with examples of reported adverse effects following their self-directed use. Of further concern is the number of emerging drugs with the potential for serious health consequences, on which there is little or no documented information. These include the muscle building growth hormone stimulators and IGF-1 analogues; these have yet to be thoroughly tested and studied in humans and consequently we know nothing of the harms they may cause. For other drugs such as the prostaglandin analogue, bimatoprost (used to increase the growth of eyelashes) and finasteride (used to increase the growth of scalp hair) adverse reactions have been documented from their therapeutic use and we anticipate similar reports from their self-directed use (Evans-Brown, McVeigh, Perkins \& Bellis, 2012).

To date, few systematic surveys of the harms caused by enhancement drugs have been conducted but outbreaks of serious adverse health consequences have been reported in the last decade. Thus, four deaths and up to 800 people were injured, after using weight-loss supplements containing hidden quantities of the untested drug n-nitroso-fenfluramine (Lau, 2004). Skin-lightening creams containing mercury were responsible for hundreds of poisoning cases (Oliveira, Foster, Savill, Syme \& Taylor, 1987), with creams containing hydroquinone and corticosteroids also causing many harms (Fraser et al, 2010).

Table1: Classifications of human enhancement drugs and examples of reported harms $\mathbf{1}^{1,2,3}$

\begin{tabular}{|c|c|c|}
\hline $\begin{array}{l}\text { Classification of } \\
\text { enhancement }\end{array}$ & $\begin{array}{l}\text { Examples of } \\
\text { specific drugs }\end{array}$ & Examples of reported harms ${ }^{3}$ \\
\hline $\begin{array}{l}\text { Structure and } \\
\text { function of muscle }\end{array}$ & $\begin{array}{l}\text { Anabolic } \\
\text { steroids }{ }^{4,5} \\
\text { Growth } \\
\text { hormones }^{5}\end{array}$ & $\begin{array}{l}\text { Vascular complications, liver damage, gynaecomastia, } \\
\text { changes in mood and behavior. } \\
\text { Symptoms of acromegaly including cardiovascular disease, } \\
\text { insulin resistance and musculoskeletal disorders }\end{array}$ \\
\hline $\begin{array}{l}\text { Weight loss and } \\
\text { dieting }\end{array}$ & $\begin{array}{l}\text { Rimonabant } \\
\text { Sibutramine } \\
\text { 2,4-dinitrophenol } \\
\text { (DNP) }\end{array}$ & $\begin{array}{l}\text { Depression, aggression and anxiety } \\
\text { Cardiovascular damage } \\
\text { Cataracts and hyperpyrexia resulting in fatalities }\end{array}$ \\
\hline $\begin{array}{l}\text { Appearance of } \\
\text { the skin and hair }\end{array}$ & $\begin{array}{l}\text { Mercury- } \\
\text { containing creams } \\
\text { Corticosteroids } \\
\text { Melanotan } \|^{5}\end{array}$ & $\begin{array}{l}\text { Damage to skin, kidney and nervous system } \\
\text { Damage to skin, Cushing's syndrome, glucose intolerance } \\
\text { and hypertension } \\
\text { Nausea and vomiting, abnormal skin pigmentation and } \\
\text { growths. }\end{array}$ \\
\hline Sexual function & Sildenafil & Cardiovascular and cerebrovascular events \\
\hline Cognitive function & $\begin{array}{l}\text { Methylphenidate, } \\
\text { modafinil }\end{array}$ & $\begin{array}{l}\text { Changes in mood and behaviour, tachycardia and changes } \\
\text { in blood pressure }\end{array}$ \\
\hline $\begin{array}{l}\text { Mood and social } \\
\text { behaviour }\end{array}$ & $\begin{array}{l}\text { Paroxetine, } \\
\text { fluoxetine }\end{array}$ & Sexual dysfunction, insomnia and withdrawal syndrome \\
\hline
\end{tabular}

Note.

${ }^{1}$ A number of human enhancement drugs are also legitimate medicines, which have been tested and approved at appropriate dosages for specific conditions. The public health concern is not in relation to these circumstances, but the self-directed use of drugs (often produced illicitly without safeguards or quality assurance) for the purpose of human enhancement.

2 Caution is required when interpreting the causal effects of drugs in the above examples, as in some cases the substances were not analysed for content, strength or contamination.

${ }^{3}$ Additional harms have been identified and reported in cases of drug interaction.

${ }^{4}$ Specific harms reported in relation to gender and young people.

${ }^{5}$ These examples may be administered by injection with users exposing themselves to the risks of blood borne viruses, bacterial and fungal infections together with localised tissue damage. 
The harms caused by these enhancement drugs are not solely as a result of their pharmacological action but also as a direct result of their provision through illicit markets. Consumers have no way of knowing the quality, safety and efficacy of products sold on the illicit market (EvansBrown, Kimergård \& McVeigh, 2009). Furthermore, for those choosing 'natural' or 'herbal' products there is no guarantee of safety, with unscrupulous manufacturers concealing potent enhancement drugs within 'healthier, natural' products. For instance, products marketed as simply herbal sexual enhancements were actually adulterated with the drug glibenclamide (used to treat diabetes) and were responsible for 13 deaths in Singapore and Hong Kong, with over 200 additional cases of serious harm within the region (Chan, 2009). It remains unclear as to whether this was a case of accidental or deliberate adulteration. It is not possible to estimate the total number of deaths or cases of serious adverse effects caused by the expanding array of human enhancement drugs. However, it is likely that these cases are merely the tip of a growing iceberg.

\section{Conclusion}

'Make your mother even more beautiful this Mother's Day with a 20mg MT2 package for only £44.00' (Website advertisement for the tanning drug melanotan II).

There is now widespread interest in human enhancement drugs, with indications of a rapidly growing and profitable illicit market. The emergence of new drugs, cheaper production methods and continuing developments in communication and transport make a further escalation in their use inevitable. In some cases the dangers of these drugs are clear; in particular where evidence from their therapeutic use is available. For many, even well established enhancement drugs, such as anabolic steroids, much of the evidence related to many of the risks remain equivocal. Other emerging drugs have yet to be fully tested on human subjects and we cannot begin to estimate their potential for acute and long-term health harms, including their potential for addiction.

Interventions to reduce the demand for enhancement drugs remain undeveloped. Better information provision especially through modern media is needed, so people can access information on harms and risks not just marketing and hype from those with vested interests. Regulations to restrict the supply of human enhancement drugs (and their constituents) are inconsistent at best. Global action is required to combat this international trade. Health professionals need to be aware of this form of drug use. They need to be familiar with those drugs that are commonly accessed and used and be prepared to treat adverse effects both physical and psychological (including their potential for addiction).

While many human enhancement drugs are new, some of the challenges that they present will not be unfamiliar to those tackling established illicit drugs such as cocaine and heroin. However, while our policies on such established illicit drugs have largely raced to catch up with global trends, by acting now on human enhancement drugs maybe we can get ahead of this curve.

\section{Acknowledgements}

The authors wish to thank Clare Perkins, Rod Thomson, Ross Coomber and Andrew Kicman for their advice and comments during this work.

\section{Declaration of interest}

The authors report no conflicts of interest. The authors alone are responsible for the content and writing of the paper.

\section{References}

Berridge, V. (1978). Victorian opium eating: responses to opiate use in nineteenth-century England. Victorian Studies, 21, 437-461.

British Medical Association (1909). Secret remedies. What they cost and what they contain. London: British Medical Association.

Chan, T. Y. K. (2009) Outbreaks of severe hypoglycaemia due to illegal sexual enhancement products containing undeclared glibenclamide. Pharmacoepidemiology \& Drug Safety, 18, 1.2501.251.

Conrad, P. (2007) The medicalization of society: on the transformation of human conditions into treatable disorders. Baltimore: Johns Hopkins University Press.

Evans-Brown, M., Dawson, R. T., Chandler, M., \& McVeigh, J. (2009) Use of melanotan I and II in the general population. BMJ, 338: b566.

Evans-Brown, M. \& McVeigh, J. (2009) Injecting human growth hormone as a performance- enhancing drug-perspectives from the United Kingdom. Journal of Substance Use, 14, 267-288.

Evans-Brown, M., Kimergård, A., \& McVeigh, J. (2009) Elephant in the room? The methodological implications for public health research of performance-enhancing drugs derived from the illicit market. Drug Test Analysis, 1, 323-326.

Evans-Brown, M., McVeigh, J., Perkins, C., \& Bellis, M. A. (2012) Human enhancement drugs: The emerging challenges to public health. Liverpool: Public Health Observatories in England.

Fraser, R., Gower, D. B., Honour, J. W., Ingram, M. C., Kicman, A. T., Makin, H. L. J., \& Stewart, P. M. (2010) Analysis of corticosteroids. Steroid Analysis (2nd Edition). Springer. 
Geiling, E. M. K., \& Cannon, P. R. (1938) Pathologic effects of elixir of sulfanilamide (diethylene glycol poisoning). A clinical and experimental correlation: final report. JAMA, 111, 919-26.

Lau, G., Lo, D. S., Yao, Y. J., Leonh, H. T., Chan, C. L., \& Chu, S. S. (2004) A fatal case of hepatic failure possibly induced by nitrosofenfluramine: a case report. Medicine, Science and the Law, 44, 252-63.

National Audit Office (2003), Safety, quality, efficacy: regulating medicines in the UK. London: The Stationery Office.

Oliveira, D. B., Foster, G., Savill, J., Syme, P. D., \& Taylor, A. (1987) Membranous nephropathy caused by mercury-containing skin lightening cream. Postgraduate Medical Journal, 63, 303-304.

Savulescu, J., ter Meulen, R., \& Kahane, G. (Eds) (2011) Enhancing human capacities. Oxford: Wiley-Blackwell.

Schnetzler, G., Banks, I., Kirby, M., Zou, K. H., \& Symonds, T. (2010) Characteristics, behaviors, and attitudes of men bypassing the healthcare system when obtaining phosphodiesterase type 5 inhibitors. Journal of Sexual Medicine, 7, 1237-46.

'Stalinon': a therapeutic disaster (1958) BMJ. 1:515.

Working Party on Amphetamine Preparations (1968). Report of the Working Party on amphetamine preparations. British Medical Association: London.

World Health Organization (2004) WHO medicines strategy 20042007. Countries at the core. Geneva: World Health Organization.

World Health Organization (2007) Quality Assurance of Pharmaceuticals: A Compendium of Guidelines and Related Materials, Volume 2, Good Manufacturing Practices and Inspection ( $2^{\text {nd }}$ edit.). Geneva: World Health Organization.

Young, J. H. (1992) The medical messiahs: a social history of health quackery in Twentieth-Century America. Princeton: Princeton University Press. 